\title{
EDUCAÇÃO AMBIENTAL E A SUA ABORDAGEM NA EDUCAÇÃO BÁSICA
}

\author{
Maira Rosenente Taverna ${ }^{1}$ \\ Lays Cherobim Parolin²
}

Resumo: Dentro da legislação brasileira está elencada a necessidade do trabalho da Educação Ambiental (EA) de maneira interdisciplinar, pois permite que os estudantes e sua comunidade consigam ter uma melhor compreensão do seu meio. Devido a essa importância, o presente artigo buscou compreender quais as dificuldades que os docentes de duas instituições públicas têm em relação à conexão da EA com suas disciplinas, através de aplicação de um questionário. Foi possível identificar que estes compreendem a necessidade de tratar nas suas aulas assuntos que permeiam a EA, porém sofrem com problemas relacionados a tempo, formação e ainda quanto à limitação do currículo das instituições de ensino.

Palavras-chave: Formação Docente; Meio Ambiente; Recursos Didáticos.

Abstract: Within the Brazilian legislation is listed the need for the work of Environmental Education (EE), this in an interdisciplinary way, because it allows students and their community to have a better understanding of their environment. Due to this importance, this article sought to understand the difficulties that teachers from two public institutions have concerning the connection of EE with their disciplines through the application of a questionnaire. It was possible to identify that they understand the need to treat in their classes subjects that permeate EE, but they suffer from problems related to time, training, and regarding the limitation of the curriculum of educational institutions.

Keywords: Teacher Training; Environment; Didactic Resources.

\footnotetext{
${ }^{1}$ Pontifícia Universidade Católica do Paraná. Escola de Educação e Humanidades. E-mail: mairataverna@gmail.com, Link para o Lattes: http://lattes.cnpq.br/2266621422517051

2 Pontifícia Universidade Católica do Paraná. Escola de Educação e Humanidades. E-mail: lays.parolim@pucpr.br, Link para o Lattes: http://lattes.cnpq.br/9480320852000818
} 


\title{
Introdução
}

A Educação Ambiental (EA) é tratada no cotidiano das pessoas, sendo possível encontrá-la nos telejornais, propagandas e outros meios, de forma que possibilita uma abordagem de questões sobre o meio ambiente. A EA acabou tendo um grande foco quando a sociedade iniciou a percepção dos grandes impactos que estão acontecendo nas condições climáticas da Terra (SANTANA et al. 2013). Como evidenciado por Gonzalez, Campos e Silva (2007) a EA contribui de maneira a fortalecer o vínculo entre sociedade e meio ambiente, deste modo, a sua abordagem auxilia na formação crítica sobre as dimensões socioambientais (BRASIL, 2012) presentes no cotidiano da sociedade. $\mathrm{Na}$ legislação brasileira é possível encontrar no artigo $1^{\circ}$ da Lei $n^{\circ} 9.795$, em que:

entendem-se por Educação Ambiental os processos por meio dos quais o indivíduo e a coletividade constroem valores sociais, conhecimentos, habilidades, atitudes e competências voltadas para a conservação do meio ambiente, bem de uso comum do povo, essencial à sadia qualidade de vida e sua sustentabilidade (BRASIL, 1999).

Segundo Jacobi (2003, p.198) "a Educação Ambiental deve ser vista como um processo de permanente aprendizagem que valoriza as diversas formas de conhecimento e forma cidadãos com consciência local e planetária". Para Reigota (2009, p.39) "a Educação Ambiental deve estar presente em todos os espaços que educam o cidadão e a cidadã" de modo que se encontra na realidade da população em diversos momentos do seu cotidiano.

Por ter tanta relevância, os docentes possuem um grande papel dentro da $E A$, já que:

\begin{abstract}
Através de ações pedagógicas que promovam a formação da conscientização ambiental, mudança de atitudes, desenvolvimento de conhecimentos e participação dos alunos, a educação trará a sua contribuição para o desenvolvimento de uma sociedade sustentável (LIELL; BAYER, 2019, p.232).
\end{abstract}

\section{Educação Ambiental no Brasil}

No Brasil, a EA começou a ser discutida no âmbito legal em 1973, com a criação da Secretaria Especial do Meio Ambiente (SEMA) e teve ações de coordenação de recursos hídricos, estudos ambientais, monitoramento de áreas de erosão e ainda iniciando a abordagem da importância ambiental dentro das 
instituições de ensino. Em 1987 o Ministério da Educação (MEC) aprovou um parecer que incluía nos currículos do $1^{\circ}$ e $2^{\circ}$ graus a abordagem da EA dentro das instituições de ensino.

Já em 1988 foi instaurada a Constituição brasileira, vigente atualmente, que tornou a EA mais significativa. De forma que a partir do artigo 225 do capítulo VI, institui que o governo deve "promover a Educação Ambiental em todos os níveis de ensino e a conscientização pública para a preservação do meio ambiente" (BRASIL, 1988), desta forma implementou a obrigatoriedade do ensino da EA nas escolas.

No ano de 1991, o MEC apresentou na Portaria n 678 de 05 de março a exigência do ensino da EA nos currículos, de maneira que não existisse uma disciplina exclusiva para abordar o tema especificamente, mas que todas deveriam trabalhá-lo. Além de indicar a "interdisciplinaridade" da EA ainda na mesma portaria, indicava no inciso 2, que:

O aprofundamento e a exploração desses temas/conteúdos não significam a inclusão de materiais ou disciplinas específicas, mas permearão todo o currículo nos diferentes níveis e modalidades de ensino, ajustando-se, por isso, à idade do estudante e ao nível de aprendizado (BRASIL, 1991).

Em 1999, o governo aprovou a Política Nacional de Educação Ambiental (ProNEA) que apresenta como a EA deve ocorrer no país, quais as formas que compreendem a educação formal e não formal, aponta ainda sobre a importância de ocorrer trabalho do tema, de forma que envolva toda a comunidade para que essa compreenda a sua necessidade.

Já em 2012, o MEC aprovou a Resolução n² de 15 de junho, que estabelece diretrizes curriculares para a EA, na qual determina a necessidade de ocorrer o trabalho interdisciplinar em todas as fases educacionais, de forma que, no artigo $8^{\circ}$ apresenta:

a Educação Ambiental, respeitando a autonomia da dinâmica escolar e acadêmica, deve ser desenvolvida como uma prática educativa integrada e interdisciplinar, contínua e permanente em todas as fases, etapas, níveis e modalidades, não devendo, como regra, ser implantada como disciplina ou componente curricular específico (BRASIL, 2012).

Ainda é tratado no artigo 11 que:

A dimensão socioambiental deve constar dos currículos de formação inicial e continuada dos profissionais da educação, considerando a consciência e o respeito à diversidade multiétnica e multicultural do País (BRASIL, 2012). 
Assim, partir da formação inicial e continuada dos professores da rede básica de ensino, possibilitaria que estes conseguissem abordar a EA de forma interdisciplinar em contexto formal e não formal de ensino.

\section{Compreensão da EA pelos docentes e discentes}

Dentro da legislação brasileira, como apresentado no parágrafo único do artigo 11 da Lei $n^{\circ} 9.795$ de 27 de abril de 1999:

Os professores em atividade devem receber formação complementar em suas áreas de atuação, com o propósito de atender adequadamente ao cumprimento dos princípios e objetivos da Política Nacional de Educação Ambiental (BRASIL, 1999).

Ainda como apresentado por Jacobi (2005):

Os educadores devem estar cada vez mais preparados para reelaborar as informações que recebem, e, dentre elas, as ambientais, para poder transmitir e decodificar para os alunos a expressão dos significados em torno do meio ambiente e da ecologia nas suas múltiplas determinações e intersecções ( $p$. 244).

É possível identificar em documentos do governo algumas citações sobre o trabalho da EA dentro da educação, entre os quais pode ser citado o inciso II do artigo 32 da Lei $n^{\circ}$ 9.394, de 20 de dezembro de 1996, que menciona que os estudantes deveriam ter "a compreensão do ambiente natural e social, do sistema político, da tecnologia, das artes e dos valores em que se fundamenta a sociedade" (BRASIL, 1996). Não apenas este, mais outros documentos como a Base Nacional Comum Curricular (BNCC), tem indicações sobre como deveria ocorrer a abordagem do tema em todos os anos da educação básica.

A busca da conexão das diversas disciplinas tem como finalidade auxiliar os estudantes a conseguirem conectar qual a importância do meio ambiente e ainda tenta possibilitar um entendimento sobre a manutenção e conservação deste, permitindo que os estudantes consigam atuar na região em que vivem de maneira que ocorram mudanças positivas em seu cotidiano (REIGOTA, 2009).

Mesmo com documentos - como os Parâmetros Curriculares Nacionais e a BNCC - que tratem sobre a importância de se trabalhar com a EA de maneira transversal, acabaram ocorrendo certos problemas. Segundo Costa (2009) a maioria dos cursos de licenciatura tem pouca ou nenhuma abordagem sobre a EA. A partir da ideia de Costa (2009), questiona-se como estes docentes colocam em suas aulas esse tema transversal, o que nos permite pensar que os professores podem ter dificuldades no planejamento de aulas que abordem a 
EA. Em outras pesquisas como a de Lima et al. (2018), é evidenciado que os docentes sabem de maneira geral o que é EA e ainda compreendem qual a importância desta dentro do âmbito escolar. Inclusive é possível identificar que por ser um tema interdisciplinar, alguns professores podem ter certa dificuldade com o planejamento de aulas das suas respectivas disciplinas.

Lima et al. (2018) em um estudo sobre a EA, perceberam que ela não era trabalhada de maneira interdisciplinar, mas individualmente em disciplinas como Biologia e Geografia, de maneira que acabou fragmentando o conhecimento dos estudantes. Costa (2009) também apresenta que as disciplinas citadas são as que mais trabalham esse tema em sala de aula.

Segundo Carvalho (2001), os professores quando não compreendem adequadamente os conceitos a serem trabalhados em sala, acabam dificultando a compreensão dos seus estudantes; menciona ainda que para que isso não ocorra, os professores deveriam ter formações continuadas sobre o assunto para que possibilite uma maneira melhor dos discentes compreenderem a importância sobre o tema trabalhado.

Pela importância da EA e pelos entraves acima apresentados, este presente estudo analisou se os docentes do ensino básico de duas instituições estaduais do município de Colombo compreendem a importância da EA, se conseguem conectar o tema em suas respectivas disciplinas e ainda identificar se encontram dificuldades ou facilidades no reconhecimento desta inserção em suas práticas.

\section{Materiais e métodos}

Como forma de coleta de dados para saber a percepção da inserção da EA nas diversas disciplinas da educação básica, foi desenvolvido um questionário para docentes (Anexo I). A aplicação ocorreu em duas instituições estaduais de Colombo, Região Metropolitana de Curitiba (Paraná).

Para o início da aplicação foi apresentado aos professores quais eram os objetivos da pesquisa, que seus dados pessoais não seriam divulgados, além de informar os riscos e benefícios da participação. Posteriormente foi explicado aos docentes como deveria ocorrer o preenchimento do questionário. Enquanto estes respondiam à pesquisa, não ocorreu nenhuma interferência dos pesquisadores que pudesse influenciar nas respostas. Cabe destacar que 0 estudo foi aprovado pelo Comitê de Ética em Pessoas da PUCPR (CAAE 22302719.8.0000.0020) e pela Secretaria de Educação do Estado do Paraná através da resolução 406/2018.

Todos as respostas foram obtidas no primeiro semestre de 2020. Após o preenchimento dos questionários iniciou-se a análise das respostas. Para isso foi realizada a plotagem dos dados em planilha do programa Excel (versão 365), inserindo as questões e as respostas de cada participante. As questões abertas tiveram suas respostas categorizadas, assim cada resposta foi classificada 
através das semelhanças e inseridas em categorias, assim permitindo uma análise também quantitativa nestas questões.

Após a categorização, ocorreu a comparação das frequências das respostas em cada questão, utilizando-se o teste do qui-quadrado calculado através do programa Excel (versão 365). Os resultados significativos foram aqueles com $p<0,05$.

\section{Resultados e discussão}

Ao todo 28 docentes de duas instituições estaduais de Colombo responderam ao questionário; sendo das disciplinas de Matemática $(n=5)$, Língua portuguesa $(n=5)$, Ciências/Biologia $(n=4)$, Educação física $(n=4)$, Geografia $(n=3)$, História $(n=2)$, Artes $(n=2)$, Filosofia $(n=1)$, Física $(n=1)$ e Sociologia $(n=1)$.

Quando questionados sobre qual era a compreensão sobre a EA foi possível categorizar as respostas em três grupos: "Relação homem com o meio ambiente", "Trabalha com problemas ambientais" e "Conscientizar sobre problemas ambientais". De maneira geral, todos os docentes comentaram sobre a necessidade de cuidados com o meio ambiente, e é possível identificar que acreditam ser importante tratar sobre o tema em sala de aula (Figura 1).

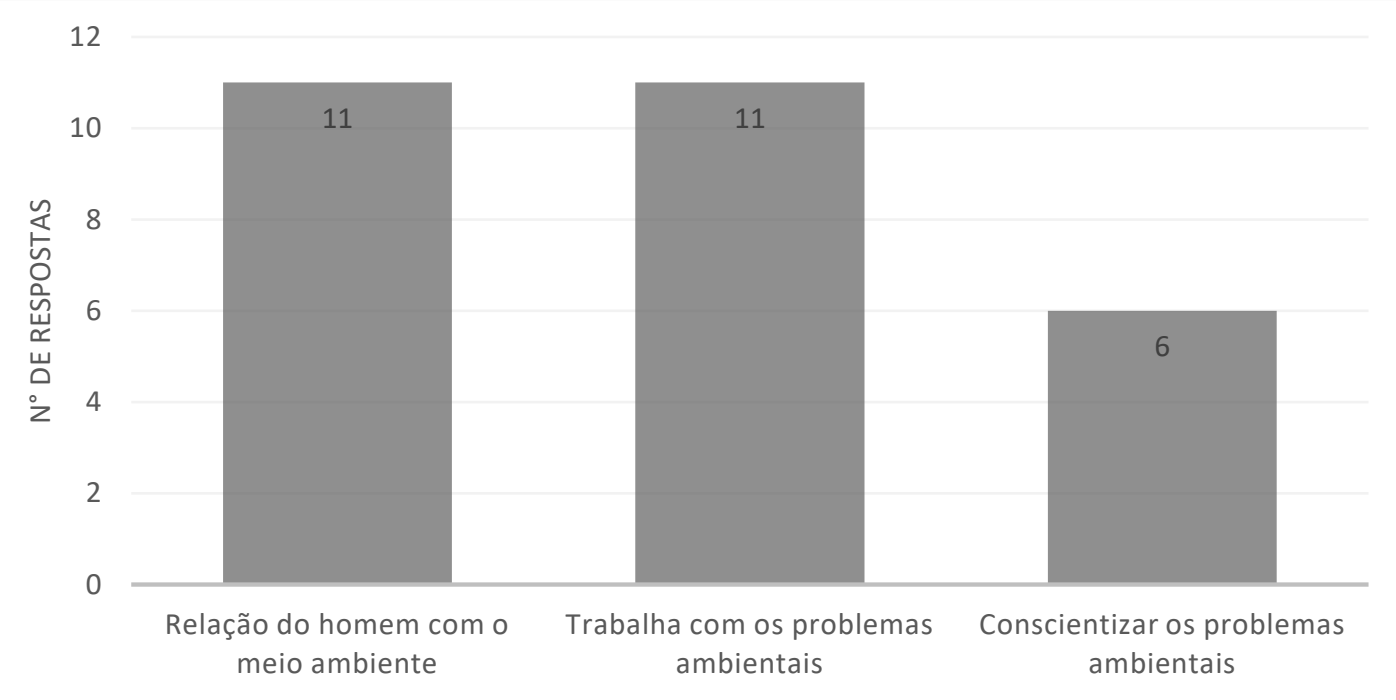

Figura 1: Frequência das respostas dos docentes quanto a percepção sobre Educação Ambiental. Fonte: Autoria própria.

$\mathrm{Na}$ categoria correspondente à "Relação do homem com o meio ambiente", foi possível identificar que grande parte das respostas são semelhantes à do professor I, o qual mencionou que a "A Educação Ambiental deve ser um processo, em que temos pertinente o meio ambiente, são abordados e esclarecidos de modo a despertar a consciência e cidadania do indivíduo". Esta e demais respostas dessa categoria seguem o que é apresentado por Reigota (2009): 
a Educação Ambiental como educação política está comprometida com a ampliação da cidadania, da liberdade, da autonomia e da intervenção direta dos cidadãos e das cidadãs na busca de soluções e alternativas que permitam a convivência digna e voltada para o bem comum (p.13).

$\mathrm{Na}$ segunda categoria chamada de "Trabalha com problemas ambientais", as respostas abordaram problemas como reciclagem e transtornos relacionados a esta e ainda sobre situações que a relacionam com problemas à saúde, como apresentado pelo professor II que justifica que é necessário esse cuidado e "respeito a natureza, pois muitos dos recursos necessários para a saúde vem dela". Segundo o professor III, a EA possui uma função de ensinar a "respeitar a reciclagem, manter sempre a sua área limpa, acho que a falta informação para moradores em relação a reciclagem".

$\mathrm{Na}$ terceira categoria, chamada de "Conscientizar sobre os problemas ambientais", é possível identificar que os docentes apresentam a compreensão de que a temática tem o objetivo de trabalhar de forma que os estudantes atuem em situações que são encontradas no meio ambiente. Por exemplo, segundo o professor IV, a temática "observa e atua compreendendo questões ambientais dentro do âmbito escolar" esta e as demais respostas classificadas nesta categoria, tem certo vínculo com abordagem das primeiras décadas da EA, que era mais voltada à conservação ambiental, estando bem conectada com a ecologia e seus conceitos, de modo que não existia uma conexão com o social (REIGOTA, 2009). Esta macrotendência chamada de conservacionista, possui características mais voltadas ao trabalho com questões ambientais de maneira mais focada nas disposições ecológicas e assim acaba não possuindo uma conexão tão forte com problemas sociais quanto a macrotendência crítica (LAYRARGUES; LIMA, 2014).

Por meio da Figura 1 é possível perceber que os dados desta questão estão próximos, de maneira que não houve diferença significativa entre as categorias apresentadas $\left(x^{2}=1,78 ; p=0,40\right)$. Outro aspecto que é possível identificar nas respostas dos docentes é que a maioria deles têm uma percepção conectada às tendências conservacionista e pragmática, de forma que respectivamente tratam sobre sensibilização dos problemas ambientais estando mais conectada com a ecologia e a segunda possui influências referentes às formas de reciclagem e cuidados com lixo produzido e demais problemáticas urbanas, tendo caráter adestrador (LAYRARGUES; LIMA, 2014).

$\mathrm{Na}$ segunda questão, em que se perguntou sobre quais as formas que os docentes sabem sobre questões ambientais, a maioria respondeu que recebe estas informações através de jornais e da internet $\left(x^{2}=14,85 ; p=0,09\right)$. Não houve diferença significativa nesta questão também. Na Figura 2 estão representadas as respostas dos docentes sobre o tema. 


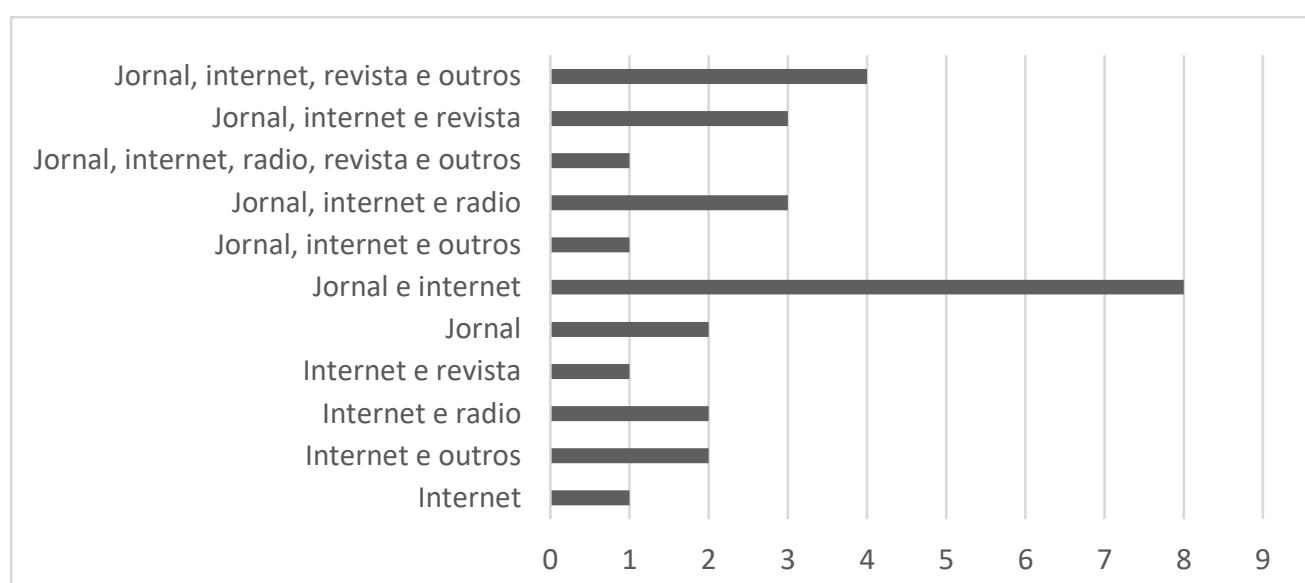

Figura 2: Frequência das respostas sobre os meios de informação sobre questões ambientais.

Fonte: Autoria própria.

Apesar de não significativa, é possível perceber que boa parte dos respondentes sabem sobre temas ambientais através de jornais, da internet e de revistas, sendo as formas mais comuns do recebimento destas informações. Esses resultados são próximos ao apresentado por Tozoni-Reis et al. (2013). Os autores ainda atentam que alguns professores utilizam estas informações recebidas a partir destes meios e repassam para os discentes, de forma que não ocorre um estudo próprio para essa prática. Em relação ao campo "outros", alguns docentes indicam meios como revistas acadêmicas, artigos acadêmicos, palestras, cursos e livros, sendo o último o mais comentado.

Quando questionados sobre qual a importância da EA no ambiente de sala de aula, foi possível classificar as respostas dos docentes em dois grupos "Formação de estudantes críticos que consigam entender o seu papel para o futuro" e "Compreensão sobre a necessidade de descarte correto de materiais". Dentro das respostas dos docentes foi possível identificar uma polarização em relação à importância da EA, sendo possível encontrar as macrotendências crítica e a pragmática (Figura 3 ).

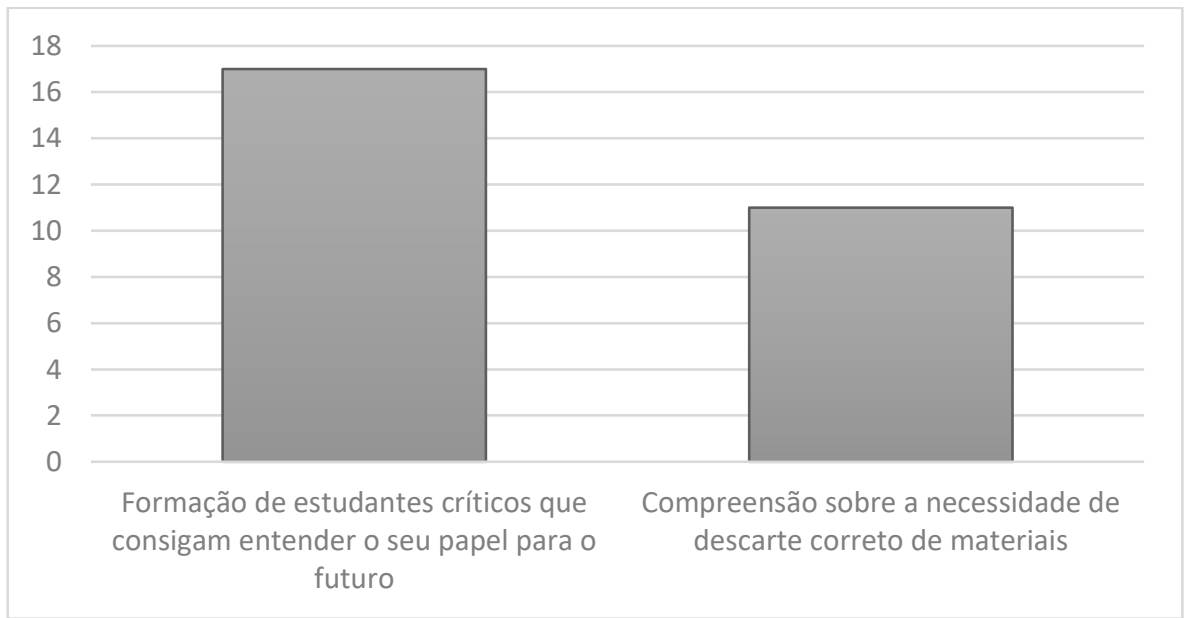

Figura 3: Importância do trabalho da Educação Ambiental para os discentes.

Fonte: Autoria própria. 
$\mathrm{Na}$ categoria "Formação de estudantes críticos que consigam entender o seu papel para o futuro", foram inseridas respostas como a do professor $\mathrm{V}$, em que apresenta que a EA "é importante para a conscientização dos estudantes para as questões ambientais e para que eles compreendam o impacto de suas ações para a natureza e os recursos naturais para as gerações futuras". As respostas obtidas possuem certa ligação com a macrotendência crítica que segundo Layrargues e Lima (2014):

apoia-se com ênfase na revisão crítica dos fundamentos que proporcionam a dominação do ser humano e dos mecanismos de acumulação do Capital, buscando o enfrentamento político das desigualdades e da injustiça socioambiental (p.33).

Desta forma acaba relacionando-se a diversos campos da sociedade para conectar-se a questões contemporâneas.

Em relação à segunda categoria nomeada como "Compreensão sobre a necessidade de descarte correto de materiais", foram classificadas respostas semelhantes as apresentadas pelo professor IV que menciona que "É fundamental que os alunos tenham o conhecimento das consequências, atitudes dos seres humanos em relação ao meio ambiente e se preocupe com os problemas como o aquecimento global, produção de lixo, entre outros". Nas respostas desta categoria é possível perceber que existe uma ligação maior em relação à macrotendência pragmática, de forma que esta derivou-se a partir da situação pós-guerra, agindo de maneira a recuperar as falhas dos sistemas de produção que geraram grande quantidade de lixo devido à obsolescência de produtos em curtos períodos de tempo (LAYRAGUES; LIMA, 2014).

Ao comparar as respostas destas duas categorias é possível identificar que não existe distinção em relação as respostas $\left(x^{2}=1,28 ; p=0,25\right)$, isso pode ser devido a uma certa combinação entre diversas tendências metodológicas para a $E A$, de forma que as explicações dos docentes se tornam muito próximas entre si.

Quando questionados sobre se conseguiam conectar o tema com as suas respectivas disciplinas, quase todos os docentes $(n=27)$ responderam que conseguiam encontrar formas de trabalhar o assunto. Quando perguntados sobre quais as formas que estes haviam utilizado para abordar o tema, apresentaram que dentro de suas disciplinas existem assuntos que possibilitam conectar com a EA. Estes ainda descrevem, em sua grande maioria, que a melhor forma de abordar os assuntos é através de textos presentes nos materiais didáticos e os selecionados pelos professores para serem trabalhados com os estudantes. Referente a como os docentes tratam o tema e em quais as situações conseguem envolver, alguns professores responderam:

Professor IV: "Questões ligadas a ocupação e conflitos mundiais em que modificam os ambientes em todo mundo, e de extração de reservas". 
Professor VI: "Quando trabalho sobre capitalismo ou meios de produção não tem como não trabalhar a questão do consumismo, produção de lixo, consumo de combustíveis fosseis e aquecimento global, como as energias limpas podem ajudar, como podemos amenizar os impactos do meio ambiente".

Professor VII: "Na física trabalhamos recursos naturais renováveis e não renováveis e a importância da não degradação desses recursos."

Professor VII: "Podemos articular os conteúdos de Educação Ambiental com todas as áreas de artes: música, dança, artes visuais, teatro. Com criatividade temos inúmeras possibilidades"

Nas respostas é possível identificar que os professores tentam encontrar diferentes maneiras de conectar temas de suas respectivas áreas. Através das respostas ainda é possível identificar que os docentes IV e VI tem uma percepção da macrotendência crítica, que envolve a percepção de uma região, sua história, relacionando pontos de debates que envolvam problemas ambientais relacionados à sociedade (LAYRARGUES; LIMA, 2014).

Quando questionados sobre quais as maneiras utilizadas sobre 0 desenvolvimento do assunto os docentes apontaram que:

Educação Ambiental" "Projetos que envolvam alunos, pais e a escola sobre

Professor X: "Trazer para a sala de aula reportagens, debates com os alunos, montando atividades avaliativas, fazendo rodas de conversas e outros."

Professor XI: "Com pesquisas de metodologias ativas que possibilitem um debate futuro, recorte de filmes, documentários que tratem do tema."

Ainda foi indicada por parte dos educadores a utilização diversos gêneros textuais (estando as charges entre as mais citadas), da análise e desenvolvimento de gráficos estatísticos, o manuseio de mapas e imagens, sendo recursos didáticos que possibilitam o emprego do tema em diferentes disciplinas. Segundo Moser et al. (2018) existem diferentes divisões em relação a materiais utilizados pelos docentes, sendo estes tradicionais (livros, quadro e outros), visuais (imagens, filmes, vídeos e outros) e informatizados (internet). Também segundo Lima et al. (2008), os materiais apresentados pelos docentes nessa pesquisa são os mais utilizados pois são de mais fácil acesso às instituições a aos próprios docentes.

Em oposição às formas de envolver o tema na disciplina lecionada, apenas um professor respondeu que não encontrava forma de trabalhar em sua disciplina, ao passo que quando perguntado sobre quais os motivos em não haver conexão entre temas, acabou não respondendo à questão.

$\mathrm{Na}$ última pergunta, os docentes foram questionados sobre as dificuldades ou facilidades que encontram em relação à abordagem da EA nas suas aulas (Figura 4). 


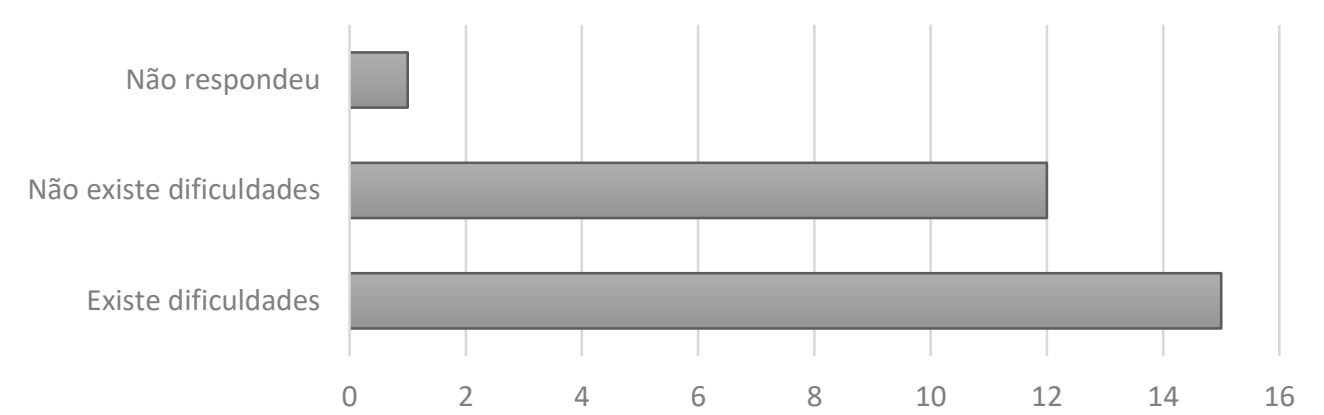

Figura 4: Dados em relação as dificuldades na inserção da Educação Ambiental nas disciplinas.

Fonte: Autoria própria.

Analisando as respostas foi possível identificar que existe diferença significativa em relação às dificuldades no planejamento de aulas que conectem as temáticas de uma disciplina com os assuntos de $E A\left(x^{2}=11,64 ; p<0,05\right)$, sendo que a maioria dos professores comentou que o principal problema é que 0 currículo das instituições são poucos flexíveis, de forma que muitas vezes estes não conseguem cumprir com o que é previsto pelo plano. A formação do docente e a sua formação continuada, a falta de condições para desenvolver diferentes aulas (como aulas de campo) que possibilitariam envolver diversos assuntos e relacioná-los, também são pontos apresentados pelos educadores.

Os professores que responderam não ter dificuldades em envolver os assuntos com EA justificaram em grande parte que saber sobre assuntos e notícias relacionadas com problemas ambientais torna-se muito fácil, pois existe bastante discussão nas mídias. Outro ponto bem comentado foi que as suas disciplinas (professores das disciplinas de Ciências, Biologia e Geografia) estão diretamente relacionadas com temas ligados à EA e através disso a abordagem acaba sendo facilitada. Em relação as respostas dos professores que falaram ter dificuldades, foram apresentados problemas como:

Professor XII: "A maior dificuldade em inserir no planejamento das aulas é em ter um tempo específico para essa organização"

Professor XIII: "Acredito que falta materiais de apoio para atividades práticas para adentrar nesses assuntos de suma importância"

Professor XIV: "Ausência da capacitação na área. Ausência de apoio financeiro e de materiais"

Nas respostas referentes às dificuldades, é possível identificar que os docentes apontaram a existência de poucos materiais de apoio para que consigam trabalhar a EA, alguns ainda mencionam problemas relacionados à formação, pois o assunto tem maior conexão com disciplinas de Ciências, Biologia e Geografia. Através destes apontamentos é possível perceber como 
apresentado por Tozoni-Reis et al. (2013), a existência de dificuldade na inserção da EA devido à precariedade de materiais, sendo estes de pesquisa $e$ de aprofundamento dos professores. Os autores abordam ainda que isso influência na formação continuada de docentes, pois estes acabam focando em materiais que não possuem explicações e conteúdos adequados que o auxiliem claramente na inserção da EA em seus respectivos componentes curriculares.

Ainda em relação à formação dos professores, Narcizo (2009) apresenta que são poucas as instituições de ensino que possuem professores com formação nesta área, desta forma destaca a importância de formação continuada. Ainda, Assis e Chaves (2015) apontam que quando o professor possui formação em sua área específica, permite a este possuir maior confiança em relação ao que trabalha em sala de aula e seus discentes apresentam uma maior confiança nele. Porém muitas vezes esta área de atuação não inclui a EA. Desta forma cabe ao docente estar em um processo contínuo de atualizações sobre diversos temas, proporcionando um melhor entendimento da abordagem da EA, fazendo com que desenvolva propostas inovadoras de metodologias a serem aplicadas no ambiente escolar.

As respostas ainda indicam outros pontos de dificuldade como documentos do governo e o próprio currículo das instituições que criam uma limitação referente à quantidade de assuntos a serem abordados no período letivo. Assim como apresentado por Watanabe-Caramello, Strieder e Gehlen (2012), as instituições de ensino muitas vezes fazem recortes muito extensos de conteúdo, o que demanda um período extenso para sua realização, assim os professores muitas vezes têm que optar em quais os assuntos deste currículo vão abordar.

Em contrapartida, os professores que falaram ter facilidade em inserir em seu planejamento a EA, afirmaram que isto ocorre porque em suas respectivas disciplinas existem "espaços" que permitem este envolvimento; ainda apresentam que a proposição de diferentes materiais para serem utilizados em sala como jornais, textos que abordam o tema, proposições de discussões sobre problemas ambientais permitem que consigam conectar em suas aulas. Outros exemplos apresentados pelos professores em relação às facilidades:

Professor XI: "Não encontro dificuldades. Hoje em dia o acesso a informações estão cada vez mais facilitadas, cabe ao professor (nós) selecionarmos fontes confiáveis para transmitir o aprendizado"

Professor XV: "Não vejo muitas dificuldades, pois se trata de acontecimentos globais e que envolvem fatos relacionados com o cotidiano deles, e os impactos afetam diretamente, ou até futuramente."

É possível identificar que os professores tentam trabalhar em suas disciplinas assuntos que fazem parte da EA e tentam relacionar com o cotidiano dos seus estudantes. Essa ação tem a intenção de abordar a EA como algo que não seja mecânico e conteudista, além de ressignificar para que existam temas

revista brasileira educação ambiental 
geradores que possibilitem os estudantes a refletir sobre eles (TOZONI-REIS, 2006). Trabalhar com temas geradores possibilita que exista a consideração da realidade dos estudantes, possibilitando que os estudantes estejam em foco (SANTOS; JACOBI, 2011). Desta forma, ao desenvolver estes temas possibilitam-se discussões para que consigam compreender a amplitude relacionada ao meio ambiente e ainda que ocorra uma nova interpretação dos elementos pertencentes a ele (DIAS, 2004).

Outro ponto apresentado pelos docentes foi a relação da disciplina que este leciona ter mais relação com a EA, desta forma consegue abordar assuntos que a envolvam em suas aulas podem ser citados exemplos como:

Professor I: "Na disciplina de biologia a inserção da Educação Ambiental é de fácil aplicação, por fazer parte dos conteúdos e estar diretamente ligado ao processo de aprendizagem"

Professor V: "Acredito que não tenha dificuldades em relacionar a Educação Ambiental uma vez que trabalho a geografia, a qual me possibilita fazer várias conexões com a Educação Ambiental."

Assim como apresentado por Lima et al. (2018), as disciplinas de Ciências, Biologia e Geografia são as mais fazem relação a conexão com a EA, ainda estas acabam estando conectadas devido ao planejamento de currículos das instituições (JÚNIOR; TOMANIK, 2013). Devido a este fato, outros professores também se apoiam nesta justificativa, como o professor XVI que afirma que "na minha disciplina que é matemática, fica um pouco difícil pelo fato de ter um currículo a seguir, assim como por ser um conteúdo, mais abordado em ciências e biologia".

Observa-se que os professores não mostraram em suas respostas que trabalham de forma interdisciplinar, o que pode estar relacionado a problemas como falta de preparo e tempo. Bonatto et al. (2012) apresentam que esse envolvimento com diversas disciplinas acaba acontecendo normalmente no cotidiano escolar; entretanto, situações que estimulem esta interação e até alguma organização da própria instituição podem favorecer o processo.

O desenvolvimento de trabalhos com a interdisciplinaridade possibilita:

um elo entre o entendimento das disciplinas nas suas mais variadas áreas. Sendo importante, pois, abrangem temáticas e conteúdos permitindo dessa forma recursos inovadores e dinâmicos, onde as aprendizagens são ampliadas (BONATTO et al. 2012 p.2). 
fim, foi possível identificar que os educadores compreendem a importância da $E A$, porém possuem em grande parte uma visão mais pragmática e conservacionista, e em apenas alguns momentos, crítica. Ainda declaram que existem dificuldades, mas é possível identificar que estes tentam tratar da EA em sua prática docente.

\section{Conclusões}

A EA possui diversas contribuições para a formação de estudantes, de forma que permite conhecerem e agirem sobre situações ambientais de suas realidades. Em âmbito legal, a discussão sobre a importância de inserir a EA vem sendo tratada de diversas formas, principalmente em relação a trabalhos interdisciplinares que possibilitem discutir sobre contextos reais que envolvam o meio ambiente.

Tendo em vista o trabalho com EA no âmbito escolar, o presente artigo buscou identificar qual a compreensão dos educadores sobre ela, se estes teriam dificuldades ou facilidades na ação de relacionar o assunto em suas disciplinas e como aplicavam. A partir disso foi possível notar que eles possuem uma compreensão mais voltada às macrotendências pragmáticas $e$ conservacionista, abordadas com problemas ambientais mais pontuais, reciclagem e ainda uma visão mais ecológica e pouco crítica.

Em relação às dificuldades encontradas em conectar o tema com as aulas, foi possível identificar que parte dos docentes afirma existir obstáculos devido à falta de tempo e pouco material de apoio; já os educadores que encontram facilidades mencionam que é possível o acesso aos conhecimentos de assuntos que permeiam a EA e isso permite trabalhar com os estudantes.

Através dos pontos abordados pelos professores é possível ainda perceber a necessidade do desenvolvimento de materiais que tratem de como pode ocorrer o envolvimento da EA nas diferentes disciplinas. Materiais como esses facilitariam a dinâmica interdisciplinar e uma discussão mais ampla do assunto com os estudantes e a comunidade escolar.

Assim observa-se que novos estudos que trabalhem com a utilização de diferentes metodologias poderiam servir de base para a construção de materiais mais completos para serem utilizados pelos professores, de forma a contribuir para uma implementação correta e ampla da EA no ensino brasileiro.

\section{Referências}

ASSIS, A. R. S. DE; CHAVES, M. R. A Educação Ambiental e a Formação de Professores. Fronteiras: Journal of Social, Technological and Environmental Science, v. 4, n. 3, p. 186, 2015. 
BONATTO, A; BARROS, C.R; GEMELI, R.A; LOPES, T.B; FRISON, M.D. Interdisciplinaridade no ambiente escolar. Anais do IX ANPED SUL. 2012. Disponível em: $<$ http://www.ucs.br/etc/conferencias/index.php/anpedsul/9anpedsul/paper/viewF ile/2414/501>. Acesso em: 13 de nov 2020.

BRASIL. Constituição da República Federativa do Brasil de 1988. 1988.

BRASIL. Resolução 678 de 1991. Disponível em: $<$ http://www.secon.udesc.br/consepe/resol/1991/035-91-cpe.pdf > . Acesso em: 13 mai. 2019.

BRASIL. LEI $\mathbf{N}^{\circ}$ 9.394, de 20 de dezembro de 1996. Disponível em: <http://www.planalto.gov.br/ccivil 03/leis/l9394.htm > Acesso em: 09 mai. 2019.

BRASIL. LEI $\mathbf{N}^{\circ}$ 9.795, de 27 de abril de 1999. Disponível em: $<$ http://www.planalto.gov.br/ccivil 03/leis/l9795.htm\#: :text=LEl\%20No\%209.79 5\%2C\%20DE\%2027\%20DE\%20ABRIL\%20DE\%201999.\&text=Disp\%C3\%B5e \%20sobre\%20a\%20educa\%C3\%A7\%C3\%A30\%20ambiental,Ambiental\%20e\% 20d\%C3\%A1\%20outras\%20provid\%C3\%AAncias.> Acesso em: 09 mai. 2019.

BRASIL. Resolução n. 2, de 15 de junho de 2012. Estabelece as Diretrizes Curriculares Nacionais para a Educação Ambiental. Disponível em: $<$ http://portal.mec.gov.br/index.php?option=com docman\&view=download\&alia

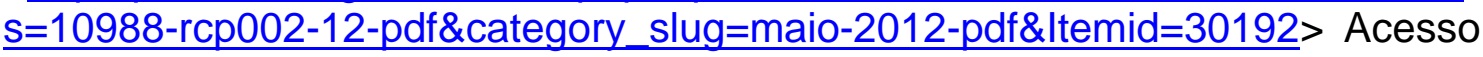
em: 09 mai. 2019.

CARVALHO, L. M. DE. A natureza da Ciência e o ensino das Ciências Naturais: Tendências e perspectivas na formação de professores. Pro-posições, v. 12, n. 1, p. 139-150, 2001

COSTA, R. G. DE A. Um olhar crítico sobre a Educação Ambiental na formação de professores em uma instituição de ensino superior gaúcha. Rev. eletrônica Mestr. Educ. Ambient, v. 22, n. 1, p. 177-187, 2009.

DIAS, G. F. Educação Ambiental: princípios e práticas. $9^{\circ}$ ed. São Paulo: Gaia, 2004.

GONZALES, L.T.V; CAMPOS, T.R; MARÍLIA F. DE; SILVA, D.R.E.DA. Educação Ambiental na Comunidade: Uma Proposta de Pesquisa-Ação. Revista Eletrônica do Mestrado em Educação Ambiental, v. 18, p. 379-398, 2007.

JACOBI, P. Educação Ambiental, cidadania e sustentabilidade. Cadernos de Pesquisa, n. 118, p. 189-205, 2003.

JACOBI, P. R. Educação Ambiental: o desafio da construção de um pensamento crítico, complexo e reflexivo. Revista de Administração Pública, v. 34, n. 6, p. 131-158, 2005.

JÚNIOR, C.A. DE. O.M; TOMANIK, E.A. Representações sociais de meio ambiente: subsídios para a formação continuada de professores. Ciência \& Educação (Bauru), v. 19, p. 181-199, 2013. 
LAYRARGUES, P.P; LIMA, G.F.DA.C. As macrotendências político-pedagógicas da Educação Ambiental brasileira. Ambiente \& Sociedade, p. 23-30, 2014. São Paulo.

LIELL, C.C; BAYER, A. A Pesquisa-ação na formação continuada em Educação Ambiental para professores de matemática. Educar em Revista, v. 35, n. 73, p. 229-250, 2019.

LIMA, N.G; DORNELAS, K.C.S; NERES, L.L.F.G; et al. Analfabetismo ambiental: a percepção dos docentes e discentes sobre o ambiente de uma escola do município de Guaraí-TO. Ambiente \& Educação - Revista de Educação Ambiental, v. 23, n. 1, p. 198-224,

LIMA, V.L.A. DE; AZEVEDO, D.C.F. DE; OLIVEIRA, M; et al. Educação Ambiental e recursos didáticos no ensino de geografia em escolas públicas do município de Sossego-PB. Revista Qualitas, v. 7, n. 2, p. 1-17, 2008.

MOSER, A. DE S.; GREGÓRIO, A. DE; PEREIRA, M.P.A.; MOREIRA, A.L.O. R. Reflexões sobre as contribuições da criação de recursos didáticos à formação inicial de professores de ciências. Revista Valore, p. 509-520, 2018. Volta Redonda.

NARCIZO, K. R. DOS S. Uma análise sobre a importância da trabalhar Educação Ambiental nas escolas. Rev. eletrônica Mestr. Educ. Ambient., v. 22, p. 15171256, 2009.

REIGOTA, M. O que é Educação Ambiental. $2^{\circ}$ ed. São Paulo, 2009.

SANTANA, E.S. DE; LIMA, E. DE C.; SANTOS, B.V. DE JESUS. Práticas De Educação Ambiental Projeto: Escola E Comunidade Cuidando Do Meio Ambiente. Cadernos de Graduação - Ciências humanas e Sociais, v. 1, p. 59-71, 2013.

SANTOS, V.M.N. DOS; JACOBI, P.R. Formação de professores e cidadania: Projetos escolares no estudo do ambiente. Educação e Pesquisa, v. 37, n. 2, p. 263-278, 2011.

TOZONI-REIS, M.F. DE C. Temas ambientais como "temas geradores": contribuições para uma metodologia educativa ambiental crítica, transformadora e emancipatória. Educar em Revista, n. 27, p. 93-110, 2006.

TOZONI-REIS, M.F. DE C.; TALAMONI, J.L.B.; RUIZ, S.S; et al. A inserção da Educação Ambiental na Educação Básica: que fontes de informação os professores utilizam para sua formação? Ciência \& Educação (Bauru), v. 19, n. 2, p. 359-377, 2013.

WATANABE-CARAMELLO, G; STRIEDER, R.B; GEHLEN, S.T. Desafios e possibilidades para a abordagem de temas ambientais em aulas de Física. Revista Brasileira de Pesquisa em Educação em Ciências, v. 12, n. 1, p. 205222, 2012. 


\section{Anexo I: Questionário enviado aos docentes.}

\section{Questionário para os docentes}

Área de formação:

Formação:( ) Graduando ( ) Graduado ( ) Especialista ( ) Mestre ( ) Doutor Idade:

Sexo: ( ) Feminino ( ) Masculino ( ) Outro ( ) Prefiro não responder Tempo de atuação na educação:

( ) 6 meses a 2 anos ( ) 2 a 4 anos ( ) 4 a 6 anos ( ) 6 a 8 anos ( ) 8 anos ou mais

1. Conforme a sua compreensão o que é a Educação Ambiental?

2. Quais as formas que você acaba tendo maiores informações sobre questões ambientais?

( ) Jornais

( ) Internet

( ) Revistas

( ) Jornais

( ) Radio

( ) Outros

${ }^{*}$ No caso de assinalar Outros, cite quais:

3. Conforme a sua compreensão qual a importância da Educação Ambiental em sala de aula?

4. Dentro da sua área de ensino, consegue encontrar formas de trabalhar a Educação Ambiental?

( ) Sim

( ) Não

5. Se na questão anterior acabou respondendo sim, cite quais as formas utilizadas para conectar a Educação Ambiental com a disciplina:

6. Se na questão 4 acabou respondendo sim cite quais as formas/maneiras que possibilitam a abordagem do tema com a disciplina:

7. Se na questão 4 acabou respondendo não cite quais os motivos para que não ocorra a conexão da Educação Ambiental na disciplina:

8. Durante o planejamento das aulas quais são as dificuldades/limitações e ainda quais a facilidades encontradas para que ocorra a inserção da Educação Ambiental na disciplina: 